\title{
Transgenic Arabidopsis Plants Expressing a Fungal Cutinase Show Alterations in the Structure and Properties of the Cuticle and Postgenital Organ Fusions
}

\author{
Patrick Sieber, ${ }^{\mathrm{a}, 1}$ Martine Schorderet, ${ }^{\mathrm{a}}$ Ulrich Ryser, a Antony Buchala, a Pappachan Kolattukudy, ${ }^{\mathrm{b}}$ \\ J ean-Pierre Métraux, a and Christiane Nawratha, \\ a Department of Biology, Unit of Plant Biology, University of Fribourg, $\mathrm{CH}-1700$ Fribourg, Switzerland \\ b Departments of Biochemistry and Medical Biochemistry and Neurobiotechnology Center, Ohio State University, Columbus, \\ Ohio 43210
}

\begin{abstract}
A major structural component of the cuticle of plants is cutin. Analysis of the function of cutin in vivo has been limited because no mutants with specific defects in cutin have been characterized. Therefore, transgenic Arabidopsis plants were generated that express and secrete a cutinase from Fusarium solani $\mathrm{fp}$ pisi. Arabidopsis plants expressing the cutinase in the extracellular space showed an altered ultrastructure of the cuticle and an enhanced permeability of the cuticle to solutes. In addition, pollen could germinate on fully differentiated leaves of cutinase-expressing plants but not on control leaves. These differences coincided with strong postgenital organ fusions. The junctions of the fusions contained pectic polysaccharides. As fused organs grew apart from each other, organ deformations and protrusions of epidermal cells developed at positions with high mechanical stress. These results demonstrate that an intact cutin layer not only is important for plant-environment interactions but also prevents fusions between different plant organs and is therefore necessary for normal epidermal differentiation and organ formation.
\end{abstract}

\section{INTRODUCTION}

All primary aerial surfaces of vascular plants are covered by a cuticle, a lipophilic layer of the outer extracellular matrix of the epidermis. The structure and composition of the cuticle vary substantially between plants, organs, and developmental stages (J effree, 1996). The cuticle consists of the insoluble structural polymer cutin and a complex mixture of lipids that are soluble in organic solvents, the so-called waxes. Cutin is a three-dimensional polymer of interesterified hydroxy and epoxy-hydroxy fatty acids with chain lengths mostly of 16 and 18 carbons (Kolattukudy, 1981, 1996). Cutin interspersed by waxes-a complex mixture of alcohols, alkanes, aldehydes, ketones, and esters derived from longchain fatty acids (Baker, 1982; Kolattukudy, 1996)_forms the cuticle proper. The cuticle proper is overlaid by epicuticular waxes. Underneath the cuticle proper, a cuticular layer may form containing polysaccharides in addition to cutin and waxes (J effree, 1996). The cuticular compounds are synthesized by the epidermal cell layer. However, how these

\footnotetext{
${ }^{1}$ Current address: Institute of Plant Biology, University of Zürich, $\mathrm{CH}-8008$ Zürich, Switzerland.

${ }^{2}$ To whom correspondence should be addressed. E-mail Christiane. Nawrath@unifr.ch; fax 41-26-300-97-40.
}

compounds are transported out of the cells and through the cell wall is not known, and the enzymes involved in cutin biosynthesis have not been purified.

Because the cuticle is the contact zone between the plant and the environment, its physical properties are highly relevant to the functions of the epidermis. The cuticle has been well characterized for its functions in gas exchange, in retention of water and solutes, as a reservoir of hydrophobic compounds, and in protecting against mechanical and irradiation damage and herbivore and pathogen attack (Kerstiens, 1996a, 1996b).

The epidermis, however, may also have important functions during plant development, forming the contact zone between different organs. When epidermal layers are in close contact, for example, in differentiating primordia at the shoot apical meristem, in quiescent buds, and during early growth stages, the epidermis keeps the developing organs separate, preventing fusions and thus facilitating normal plant development. The absence of fusions between epidermal cells has also been observed during grafting (Walker and Bruck, 1985). That the cuticle may play an important role in the inhibition of organ fusion can only be hypothesized. Although a procuticle may be present very early in development (Heide-J ørgensen, 1991), testing the postulated role of the cuticle in inhibiting unwanted organ fusion has not been possible. 
Systematic searches for mutants with defects in the cuticle have identified numerous mutants with altered epicuticular wax composition. Epicuticular wax mutants affecting the stems of Arabidopsis show differences from the wild type in chemical composition as well as total wax load (having from 15 to $80 \%$ of that of the wild type) (Koornneef et al., 1989; Hannoufa et al., 1993; McNevin et al., 1993). Studies of these mutants have contributed to recent progress in understanding wax biosynthesis (Lemieux, 1996).

Several lines of evidence show that mutants with alterations in epicuticular wax composition may also be affected in certain aspects of plant development. Arabidopsis mutants identified by altered leaf reflectance, such as waxl, cer10, and cer13 (for eceriferum), have altered leaf morphology and show organ fusions (J enks et al., 1996). Similarly, the adherent mutant (ad1) of maize has leaf fusions, altered leaf reflectance, and reduced wax load (Sinha and Lynch, 1998). In the ad 1 mutant, the fusion zones consist of a complex polysaccharide mixture (Sinha and Lynch, 1998). Waxes are present not only in the cuticle but also in the pollen coat. Some Arabidopsis mutants with altered epicuticular wax formation, such as cer1, cer3, cer6-1, and pop1 (for defective pollen-pistil interactions; also termed cer6-2), are also affected in the structure of the pollen coat and in pollen fertility (Preuss et al., 1993; Hülskamp et al., 1995).

The fiddlehead ( $\mathrm{fdh}$ ) mutant and several other Arabidopsis mutants are characterized by their striking postgenital organ fusions in leaves, flower organs, or both (Lolle et al., 1992, 1998). Although these mutants have a normal leaf reflectance, their organ fusion phenotypes are similar to those of mutants with an altered epicuticular wax layer (J enks et al., 1996; Sinha and Lynch, 1998). Interestingly, in these mutants, organ fusion often, but not always, coincides with pollen germination on leaves and with chlorophyll leaching, showing that these phenotypes are related, despite representing different biological processes (Lolle and Cheung, 1993; Lolle et al., 1997, 1998). The exact biochemical changes responsible for these phenomena are not yet understood. Lately, Arabidopsis Columbia (Col) plants carrying the fdh mutation have been found to have statistically fewer $(\mathrm{P}<0.001)$ trichomes than $\mathrm{Col}$ control plants, which suggests a role of the fdh gene in trichome initiation (Yephremov et al., 1999). Cloning of the fdh gene has been recently reported by two independent groups (Yephremov et al., 1999; Pruitt et al., 2000). The FDH-encoded protein shows marked similarity to condensing enzymes, particularly those of the FATTY ACID ELONGATION family (Yephremov et al., 1999; Pruitt et al., 2000), but the protein function has not been experimentally confirmed.

Analysis of cutin mutants would be an appropriate experimental system for directly investigating the role of the cuticle in plant development. However, because no reports of cutin mutants as such have been published, an indirect way to investigate the functions of the cuticle during development is used in which the cuticular integrity is disrupted by the expression of a cutin-degrading enzyme.
Cutinases are well characterized as being produced by phytopathogenic fungi during the colonization process; these enzymes may assist in penetration of the cuticle (Kolattukudy, 1985; Kolattukudy et al., 1995), facilitate spore adhesion (Deising et al., 1992), or induce appressoria (Francis et al., 1996). Cutinases have also been purified from pollen (Maiti et al., 1979) and have been suggested to be involved in the penetration of the pollen tube into papillae cells (Hiscock et al., 1994). Whereas fungal cutinases are well characterized and their genes have been isolated from many species, plant cutinases are poorly characterized, no genes have been cloned, and no mutants with altered cutinase activity have been isolated (Kolattukudy, 1984; Hiscock et al., 1994; Yao and Köller, 1995). Fungal cutinases have been a useful tool for studying the functions of the cutin layer of plants in vitro. For example, application of cutinase from Fusarium solani $\mathrm{sp}$ pisi onto isolated cuticular layers decreases the mechanical strength of the cuticle and increases its permeability (Baker et al., 1982). Furthermore, in deep-water rice, tissue tension in bent stem fragments can be released by the application of a fungal cutinase, indicating that the cutin layer might limit plant growth (Hoffmann-Benning and Kende, 1994).

In this study, we describe transgenic Arabidopsis plants that express and secrete a fungal cutinase and therefore degrade cutin in situ. Besides having altered cuticle properties and ultrastructure in comparison with wild-type plants, cutinase-expressing transgenic plants show developmental abnormalities, such as postgenital organ fusions and alterations in the morphology of the epidermal layer, demonstrating that the cutin layer plays an important role in plant development.

\section{RESULTS}

\section{Expression and Secretion of a Fungal Cutinase in Transgenic Arabidopsis}

To study the biological significance of cutin, we modified a fungal cutinase and expressed it in transgenic Arabidopsis to target the enzyme to the extracellular space. For this purpose, the cDNA of the cutinase from F. s. pisi (Soliday et al., 1984) was truncated by removing the sequence encoding the fungal secretion signal and then was fused to the coding region of the secretion signal of the tobacco chitinase $A$ (Shinshi et al., 1990). The signal sequence was presumably cleaved during secretion, because the original sequence of the complete signal peptide of the chitinase $A$ had been maintained in the fusion (.$-\mathrm{M}$. Neuhaus, personal communication). These modifications of the cutinase gene were necessary because expression of the unmodified gene containing the endogenous fungal secretion signal did not yield transgenic plants with cutinase activity.

After the gene fusion had been cloned behind the cauli- 
flower mosaic virus (CaMV) $35 \mathrm{~S}$ promoter for constitutive expression in the plant, the plasmid p35S::SS::Cut was transformed into Arabidopsis (accession Col-0), and seven independent transgenic lines that expressed the fungal cutinase were raised. In addition, the construct was transformed into Arabidopsis (accession Col-0) that carried the glabrous1 ( $g l 1)$ mutation because the lack of trichomes in this mutant was advantageous for some of the experiments undertaken (see below). Thirteen independent lines that expressed cutinase in Col-0/gll were selected. RNA gel blot analysis was used to determine cutinase gene expression (data not shown), and cutinase enzyme activity in transgenic Arabidopsis was detected by using p-nitrophenyl butyrate as substrate (Dickmann et al., 1982). No significant differences were observed between transgenic lines in Col-0 and Col-0/gl1 plants, either in the basic esterase activity measured or in the capacity to express the fungal cutinase. In crude extracts, the cutinase activity varied between 1 and $300 \mu \mathrm{mol} \mu \mathrm{g}^{-1}$ of protein $\mathrm{min}^{-1}$ among the different transgenic lines and was 10 - to 3000 -fold higher than background activity in control plants transformed with the empty vector, as shown in Figure 1.

Cutinase activity was measured in the intercellular wash fluid to determine whether the cutinase had been correctly delivered to the extracellular space (Keefe et al., 1990). The specific activity in the intercellular wash fluids was, however, low and only five to 15 times higher than in the crude extracts. Surprisingly, most of the cutinase activity was found in the extraction buffer that did not enter the intercellular space of the leaves during infiltration. Taking into account the comparably larger volume of the extraction buffer, 500 to 1000 times more cutinase was found in the buffer solution than in the intercellular wash fluid after a handling time of $\sim 10$ min. Because the release of cutinase activity did not coincide with any chlorophyll release, an indication of cellular damage, we concluded that the cutinase was correctly

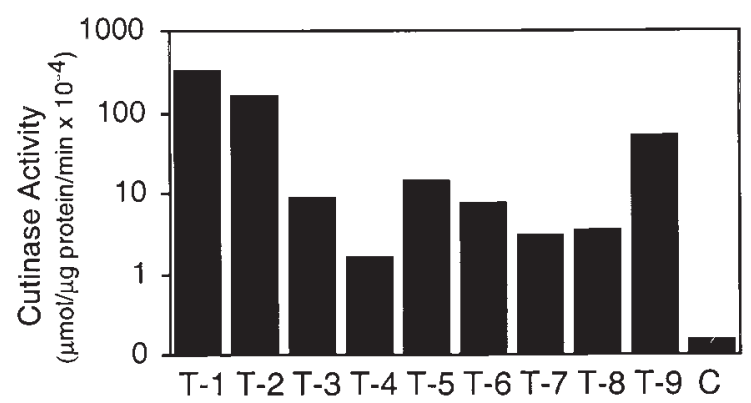

Figure 1. Cutinase Activity of Transgenic Arabidopsis Expressing a Fungal Cutinase.

Shown are nine representative transgenic Arabidopsis Col-0/gl1 lines transformed with the plasmid p35S::SS::Cut compared with Arabidopsis Col-0/gl1 control plants (C) transformed with the empty vector. T-1 to T-9, independent transformed plant lines 1 to 9 . delivered to the extracellular space and, moreover, that cutinase-expressing plants were incapable of retaining extracellular proteins in their intercellular space when submerged (see below).

\section{Physical Properties of the Cuticle of Cutinase-Expressing Arabidopsis}

To study the permeability of the cuticle in cutinase-expressing Arabidopsis, several types of experiments were performed, including protein leaching, chlorophyll leaching, and sensitivity to herbicides. For these experiments, transgenic plant lines with a Col-0/gl1 background were chosen because the lack of trichomes eliminated the possibility of cuticle damage from breaking trichomes. The three transgenic lines investigated-T-2, T-5, and T-9-had a mean cutinase activity \pm SE of $166( \pm 69) \times 10^{-4}(n=3), 13.8( \pm 3.2) \times 10^{-4}$ $(\mathrm{n}=3)$, and $61( \pm 2) \times 10^{-4} \mu \mathrm{mol} \mu \mathrm{g}^{-1}$ of protein $\min ^{-1}(\mathrm{n}=$ $3)$, respectively.

When leaves of cutinase-expressing plants were submerged for $2 \mathrm{hr}$ in an aqueous solution, between 70 and $90 \%$ of the cutinase activity leached out of the leaf, and the cutinase activity in the wash solution increased notably. The appearance of the cutinase coincided with an increase in protein concentration in the wash solution. The protein concentration of the wash solution of $100 \mathrm{mg}$ of leaves of cutinase-expressing plants after $2 \mathrm{hr}$ of submergence was $11.9 \pm$ $3.0 \mathrm{mg} / \mathrm{mL}(\mathrm{n}=3)$ for plants of the T-2 line and $5.6 \pm 0.3$ $\mu \mathrm{g} / \mathrm{mL}(\mathrm{n}=3)$ for plants of the T-5 line compared with $0.91 \pm$ $0.19 \mu \mathrm{g} / \mathrm{mL}$ for wild-type plants $(\mathrm{n}=3$ ). Thus, unlike the wild type, cutinase-expressing plants showed a rapid release of proteins, which correlated with the amount of cutinase activity of the plants. Although no detailed studies on the nature of the leached proteins were undertaken, these proteins were probably extracellular proteins, given that no detergent had been added to the wash solution and that no significant chlorophyll leaching coincided with the protein leaching.

However, when membranes were permeabilized by ethanol, chlorophyll also leached out rapidly in cutinase-expressing plants. Figure 2 shows the diffusion rate of chlorophyll from different cutinase-expressing plants (T-2, T-5, and T-9 lines) and wild-type plants. The chlorophyll diffusion was much faster in all three cutinase-expressing plants than in wildtype plants and correlated with the amount of activity of this enzyme in the plants. These two extraction experiments highlight different aspects of the permeability of the modified cuticle because chlorophyll, despite its heme moiety, is essentially hydrophobic, whereas the cutinase and other extracellular proteins are mainly hydrophilic.

Given that the diffusion rate out of the leaf was enhanced in cutinase-expressing plants, the diffusion rate of molecules into the plant might also be increased, possibly leading to an increased sensitivity to herbicides. Wild-type Arabidopsis plants did not show any symptoms after 2 weeks of treatment with Roundup at concentrations up to 


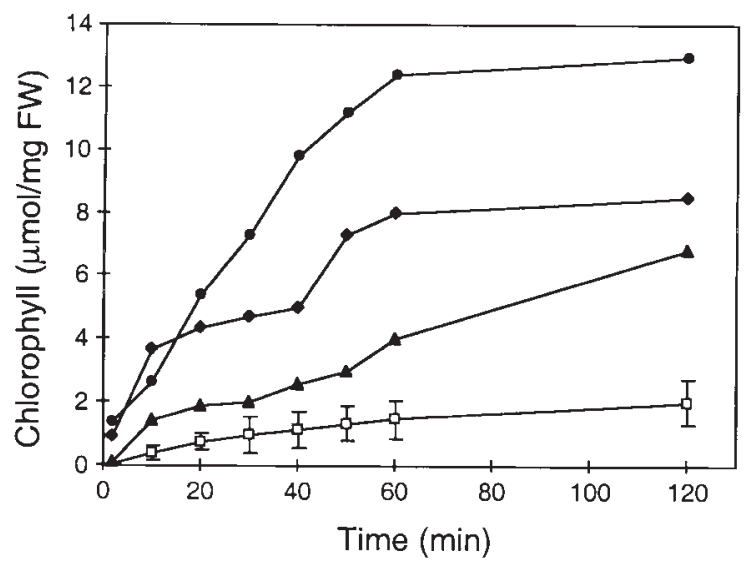

Figure 2. Chlorophyll Release from Submerged Leaves of Col-0/gl1 Control Plants and Cutinase-Expressing Arabidopsis Plants.

Open squares, wild-type Col-0/gl1 with a mean value from three analyses $( \pm \mathrm{SE})$; solid circles, diamonds, and triangles, representative measurement from cutinase-expressing Arabidopsis lines T-2, $T-9$, and $T-5$, respectively. The measurement was repeated three times with similar results. FW, fresh weight.

$31 \mathrm{~nL} / \mathrm{mL}$. However, cutinase-expressing plants of the T-9 line showed obvious chlorosis after treatment with the same dose of the herbicide (data not shown). These cutinaseexpressing plants were sensitive to Roundup at a concentration as low as $7 \mathrm{~nL} / \mathrm{mL}$, an indication that the cuticle in cutinase-expressing plants is clearly more permeable than in the wild type.

\section{Pollen Can Germinate on Leaves of Cutinase-Expressing Arabidopsis}

Pollen normally germinates only on compatible stigmas. Pollens from plants having a dry stigma, such as Arabidopsis and Brassica rapa, produce a specific pollen coat that is necessary for pollination (Wolters-Arts et al., 1998). Pollen applied to the mature leaf is unable to germinate; however, when applied to young leaves having a thin cuticle or to leaves from which the cuticle is removed, it germinates (Wolters-Arts et al., 1998), indicating that the cuticle is a major barrier to ectopically germinating pollen. To study the possible germination on mature leaves of cutinase-expressing Arabidopsis, pollen from plants with dry stigmas, such as Arabidopsis and Brassica, and pollen from plants with wet stigmas, such as tobacco and petunia, were applied both to mature leaves of cutinase-expressing Arabidopsis and to mature rosette leaves from wild-type plants. On mature leaves from wild-type plants, the pollen substantially failed to germinate $(<10 \%$ pollen germination), as shown in Figure $3 \mathrm{~A}$. In contrast, $\sim 70$ to $80 \%$ of the applied Arabidopsis pollen germinated on mature rosette leaves from cuti- nase-expressing plants, as shown by the fluorescence displayed by callose-rich pollen tubes (Figure 3B). Interestingly, the epidermis cells underneath germinating pollen also sometimes showed callose deposition, indicating that the epidermal cells reacted to pollen tube penetration of the cuticle (Figure 3B). Brassica pollen was also able to germinate on leaves of cutinase-expressing Arabidopsis, but pollen from tobacco and petunia did not (data not shown).

\section{Cutinase Expression Leads to Postgenital Organ Fusion between Shoot Tissues}

The most prominent visual phenotype of cutinase-expressing Arabidopsis was a strong organ adhesion between organs of the shoot (i.e., leaves, stems, and flowers), leading to a distorted appearance of the shoot, as shown in Figures
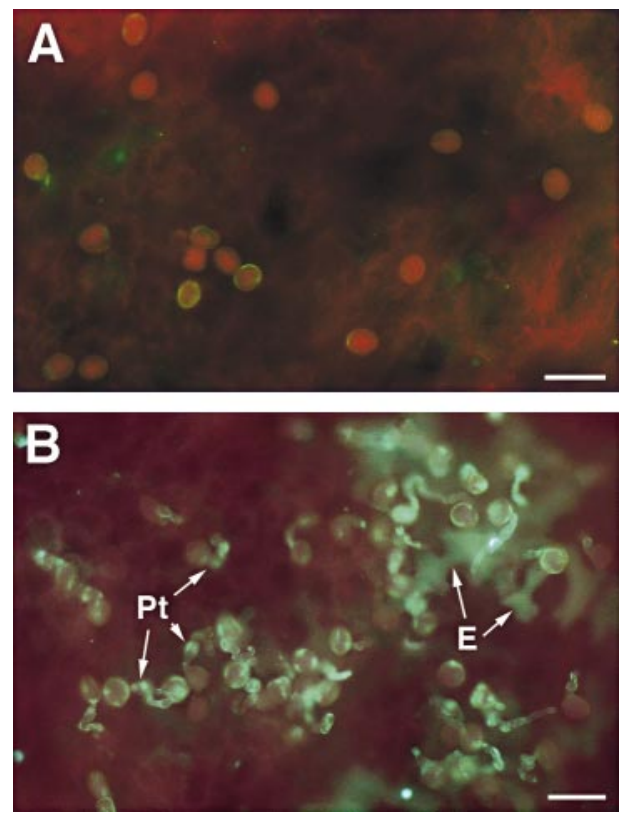

Figure 3. Pollen Germination on Rosette Leaves of Col-0/gl1 Control Plants and Cutinase-Expressing Arabidopsis Plants.

(A) Mature leaf of a Col-0/gl1 plant fixed $20 \mathrm{hr}$ after pollen application, stained with aniline blue, and visualized by UV excitation at 340 to $380 \mathrm{~nm}$. The absence of green fluorescence demonstrates that no callose was deposited in the pollen and that no pollen tubes rich in callose developed.

(B) Leaf of cutinase-expressing plant (line T-5) fixed $20 \mathrm{hr}$ after pollen application, stained with aniline blue, and visualized by UV excitation at 340 to $380 \mathrm{~nm}$. The green fluorescence indicates callose in pollen and particularly in outgrowing pollen tubes (Pt). In addition, callose was deposited in epidermal cells $(E)$ underneath the germinating pollen as a defense response to pollen tubes penetrating the cuticle.

Bars in $(\mathbf{A})$ and $(\mathbf{B})=25 \mu \mathrm{m}$. 
$4 \mathrm{~A}$ and $4 \mathrm{~B}$. The frequency of organ fusion events and the consequent severity of the growth distortion of the shoot were correlated with the amount of cutinase activity. Thus, plants with low cutinase activity showed normal growth with occasional fused leaves or flowers, whereas plants expressing high cutinase activity had organs connected over large areas and at multiple locations. In such plants, several leaves were attached together, emerging inflorescences grew together with leaves (Figure 4A), or several fused flowers stayed connected while continuing to grow, thus distorting the growth appearance (Figure 4B). Fusions also often occurred at trichomes in cutinase-expressing Col-0 plants. However, trichomes were not an important factor in the formation of tight fusions because the trichomeless cutinaseexpressing Col-0/gl1 can form very similar fusions.

Fusions occurred only early in organ development, when organs were close together. This was particularly apparent when the cutinase was expressed over a short time under the control of a copper-inducible promoter ( $P$. Sieber and $C$. Nawrath, unpublished data). In that case, fusion events were obvious only 1 to 2 weeks after cutinase induction. Fusions among flower organs occurred particularly often. The flowers of plants expressing a medium cutinase activity never opened-their flower organs were fused-but occasionally some siliques emerged from closed flowers. Accordingly, the seed set was greatly reduced in cutinase-expressing plants. Plants having a high cutinase activity $\left(>10 \times 10^{-4}\right.$

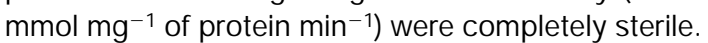

In contrast to changes in the growth of the shoot, the growth of the roots appeared normal. Fusions were never observed during root growth and development, even when the roots came into close contact with each other. In addition, the internal tissues of stems, leaves, and roots appeared normal, as did the root epidermis, which does not produce cutin (J effree, 1996). Therefore, the adhesion phenotype and the resulting effects on plant growth were strongly correlated with the presence of the cuticle and with specific alterations in the cuticle caused by the expression of cutinase.

\section{Organ Fusion Alters Organ Shape and Epidermal Development}

Alterations in the shape of organs were observed when fused organs grew in different directions. This often led to the formation of cell bridges. The extent of the deformation was correlated with the size of the fusion site and with the force generated by growth in opposite directions. These cell bridges could be very small, as demonstrated in Figures $5 \mathrm{~A}$ and $5 \mathrm{~B}$. In other cases, however, the shape of an organ was strongly altered; for example, when leaves grew away from a small but well-established attachment site, pointed edges formed on leaves that normally were oval, as shown in Figures $5 \mathrm{C}$ and $6 \mathrm{~A}$. When large fused areas were under strong mechanical stress, broad cell bridges formed at the fusion
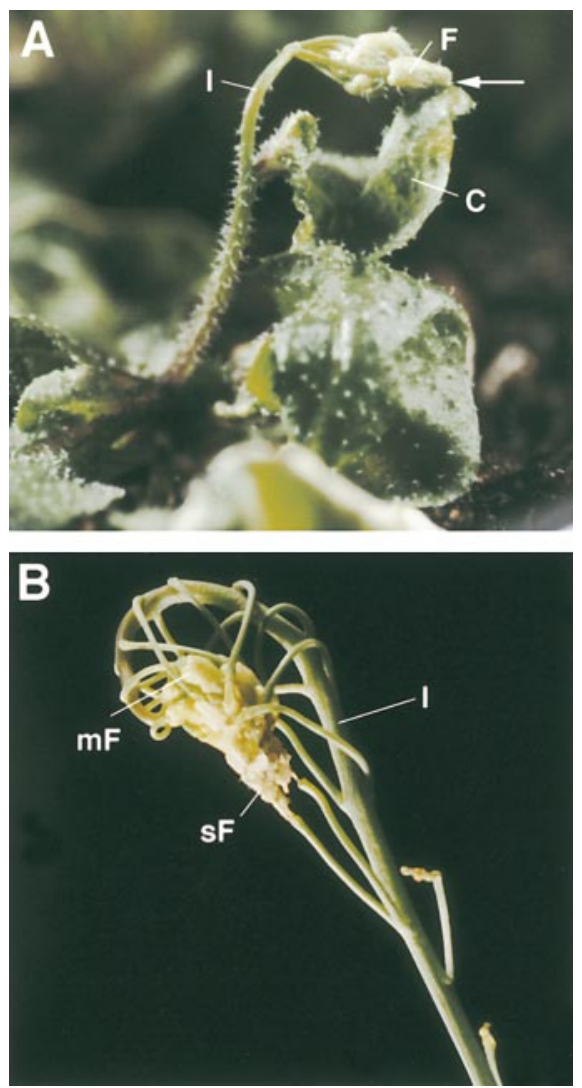

Figure 4. Visual Phenotype of Cutinase-Expressing Arabidopsis Plants.

(A) Cutinase-expressing plant with a fusion between the inflorescence and a cauline leaf. The point of fusion is marked by an arrow. (B) Inflorescence of a cutinase-expressing plant with multiple organ fusion events between a series of flowers of different ages and among flower organs, leading to sterility. The points of cell contacts are hidden.

C, cauline leaf; $F$, flower; I, inflorescence; $m F$, mature flower; sF, senescing flower.

zone (Figure 5D). In areas of altered organ shape or in cell bridges, a large proportion of the epidermal cells kept their normal shape and differentiation pattern and formed stomata (Figures 5C and 5D). Sometimes, however, abnormally large cells were located in the fusion zones, lying within the epidermal plane as tubelike structures (Figures 5D, 7C, and 7D). If the tension at the tissue of the fusion site was too strong, the epidermal layer was torn apart and mesophyll cells bulged at the wound site (Figure 7D).

In extreme situations, filaments connected the organs, as shown in Figure 6A. Semithin sections through these filaments showed that they were composed primarily of epidermal cells (Figure 6C). Interestingly, the epidermal cells in 

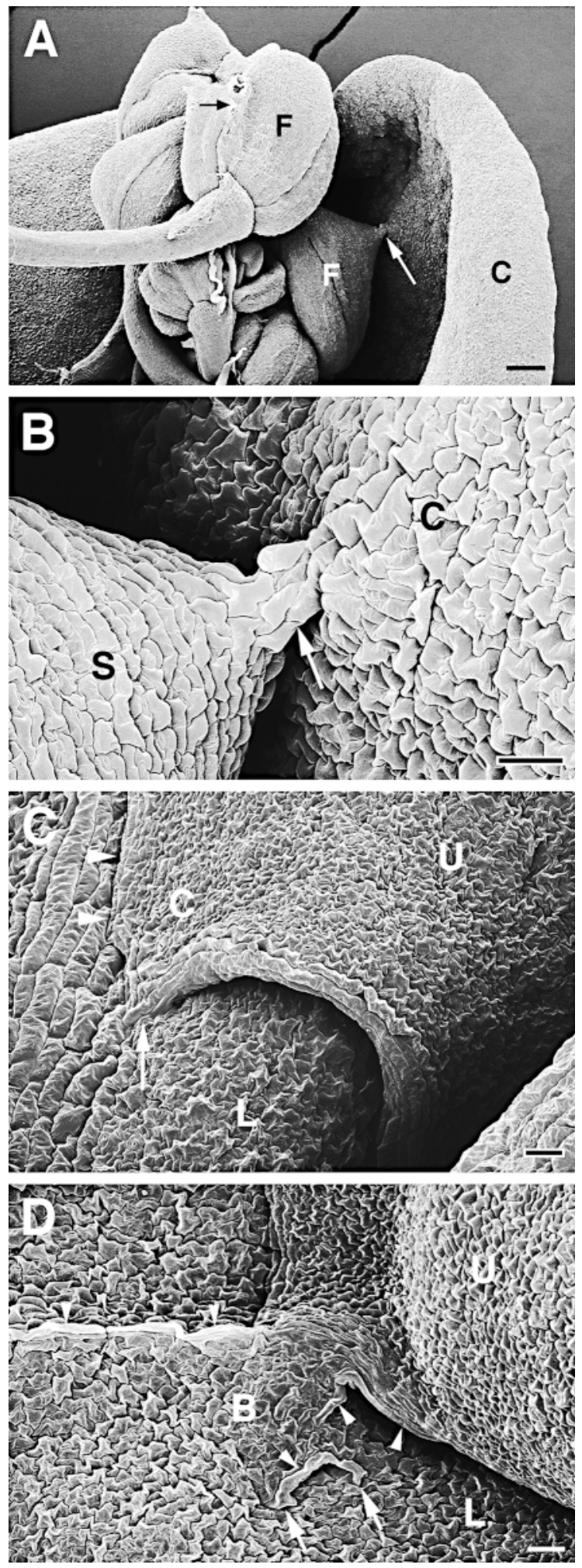

Figure 5. Scanning Electron Microscopy of Organ Fusions of Cutinase-Expressing Arabidopsis Plants. these filaments kept their identity and differentiated into trichomes and into guard cells forming stomata (Figure 6C). However, the size of the epidermal cells varied considerably, and sometimes the epidermis formed was multilayered (Figures $6 \mathrm{C}$ and $7 \mathrm{C}$ ). In addition, cell division occasionally occurred in the periclinal plane, giving rise to unusual protrusions (Figure 6C).

Stems that adhered to other organs and therefore showed distortions developed a protruding epidermis at the distal side of the fusion, sometimes along the whole internode segment (Figures 6B, 7A, and 7B). Furthermore, when stems were strongly twisted, the epidermal cell layer folded upward, forming a protruding ridge (Figure 6A). Additional protrusions (Figure 6A) and filaments (Figure 7C) could form at such protruding ridges. Semithin sections through stem protrusions revealed features very similar to those of filaments, including cell size variation, multilayered epidermis, and stomata formation (Figure 6D).

In summary, organ fusion was followed by a wide range of alterations of the normal shape of the organs, particularly when strong mechanical stresses were involved. These alterations were sometimes correlated with abnormal differentiation of epidermal cells.

\section{Ultrastructure of the Cuticle and of Organ Fusions of Cutinase-Expressing Plants}

Unique alterations of the ultrastructure of the cuticle were observed in cutinase-expressing Arabidopsis stems and leaves. In stems of wild-type plants, the appearance of the cuticle is as an electron-opaque, amorphous layer of uniform structure, as shown in Figure 8A. In cutinase-express-

(A) Five flowers with fused flower organs were fused to each other, and one flower was fused to a cauline leaf. Cell contacts between two sepals of one flower (small black arrow) and between a sepal and the cauline leaf (large white arrow) were visible. C, cauline leaf; $\mathrm{F}$, flower. $\mathrm{Bar}=200 \mu \mathrm{m}$.

(B) Enlargement of (A). Small cell bridge (arrow) between sepal and cauline leaf. Epidermal cells appeared slightly larger in the cell bridge than in the unfused tissue. C, cauline leaf; S, sepal. Bar $=50 \mu \mathrm{m}$.

(C) Two overlapping rosette leaves were fused to each other. The normally oval upper leaf formed a corner in the area of fusion. Suture with hidden cell contacts is indicated with arrowheads; visible cell contacts are indicated with an arrow. C, leaf corner; L, lower leaf; U, upper leaf. Bar $=50 \mu \mathrm{m}$.

(D) A large cell bridge formed between two fused leaves. Large parts of the suture were not visible. Several cell contacts are visible (arrows). In part of the cell bridge, large epidermal cells developed (arrowheads), whereas the epidermal cell layer of other areas was normally differentiated. $B$, cell bridge; L, lower leaf; $U$, upper leaf. Bar $=100 \mu \mathrm{m}$. 

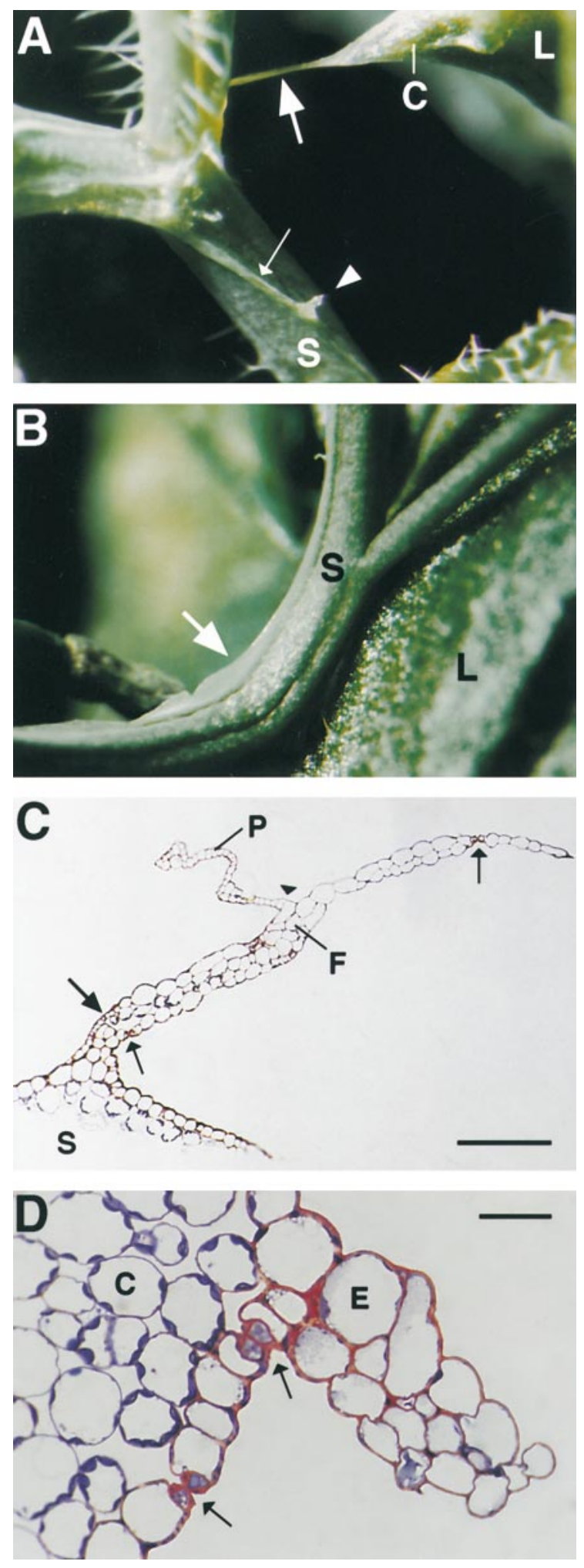

Figure 6. Unusual Epidermal Protrusions Formed in Cutinase-Expressing Arabidopsis. ing plants, the cuticle of stems is of uneven thickness, and its structure, where present, is completely different from that of wild-type plants. The electron-opaque cuticular material is dispersed and separated by smaller or larger electrontranslucent spaces. We interpret these spaces as being empty, probably because of the extraction of cutin breakdown products during tissue processing. The border between cuticular materials and cell wall polysaccharides is discontinuous and irregular in outline, and fibrillar, polysaccharide-like material is observed in the outer layers of the modified cuticle. Therefore, the cuticle of the stems of cutinase-expressing plants has a loose structure and a mixed composition (Figure 8B). Fusion zones between stems have an ultrastructure similar to that of the unfused cuticle of the stem of cutinase-expressing plants (Figures 8C and 8D). Mainly fibrillar materials and electron-translucent spaces are visible (Figure $8 \mathrm{E}$ ). Only the outer cell wall layers are involved in the fusion; the epidermal cell layers keep their identity, as shown by the formation of stomata (Figure 8D).

In leaves of wild-type plants, the cuticle is a thin but very electron-dense layer (Figure 9A). The fusion zones of cutinase-expressing plants vary in their ultrastructure in different organs. In leaves, close contacts between the two epidermal layers predominate (Figure 9C). Often a direct contact of cell wall polysaccharides is observed, but remnants (Figures $9 \mathrm{~B}$ and $9 \mathrm{C}$ ) or longer stretches of small amounts of cuticular material also occur (Figure 9D). At the border of fused regions, fibrillar polysaccharides interconnect the two epidermal cell layers (Figures 9D and 9E). This material often shows enhanced contrast in the thin sections and, together with the outer layers of the epidermal cell walls, is labeled with JIM5 antibodies (Figure 9G), which have been shown to be specific for unmethylated pectin (Knox et al., 1990). J IM 7 antibodies specific for methylesterified pectins also label the interconnecting polysaccharide filaments but in addition label the inner layers of the epidermal cell walls (data not shown). The amount of the pectic

(A) A pointed corner with a long epidermal attachment filament (large arrow) developed on a leaf after organ fusion with a stem under high mechanical stress. Epidermal ridges on a distorted stem are indicated by a small arrow; a protrusion originating from the ridge is marked by an arrowhead. C, leaf corner; L, leaf; S, stem.

(B) Epidermal protrusion in a bent stem segment (arrow). L, leaf; S, stem.

(C) Semithin section through an attachment filament. The large arrow indicates an area of high variability in size of epidermal cells; the small arrows indicate the stomata; and the arrowhead indicates the periclinal division plane. F, filament; $P$, protrusion; $S$, stem. Bar $=50 \mu \mathrm{m}$. (D) Semithin section through a ridge protruding from a distorted stem segment. Arrows indicate the stomata. C, cortical cell; E, epidermal cell. Bar $=10 \mu \mathrm{m}$. 

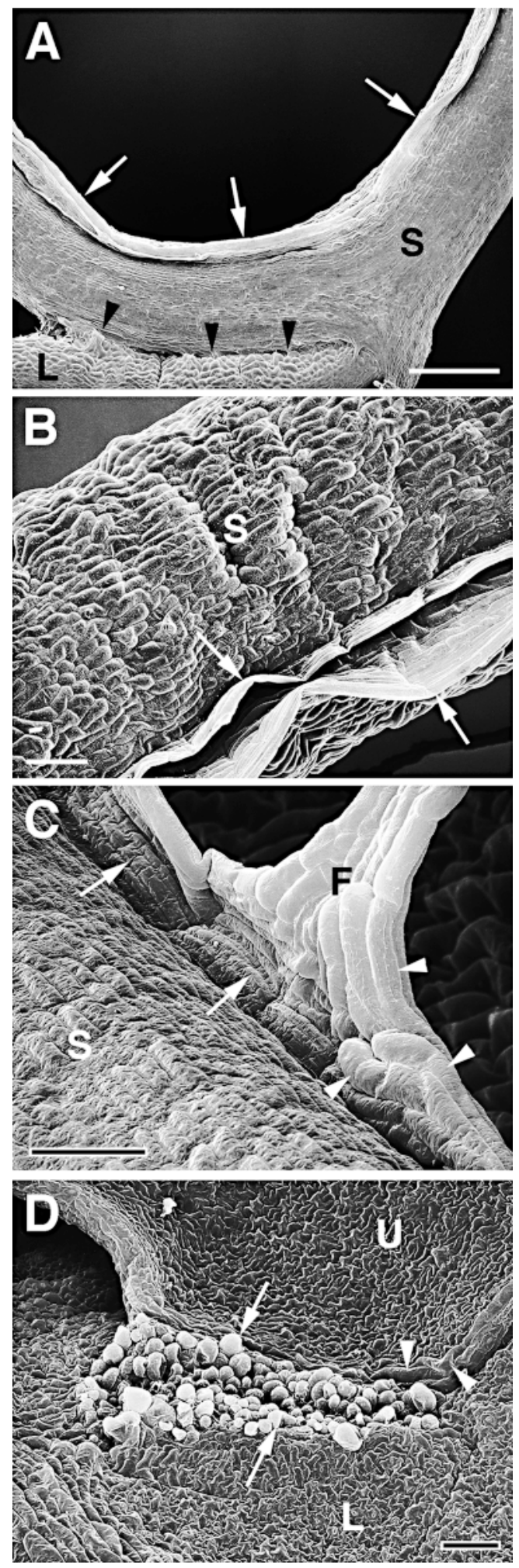

Figure 7. Scanning Electron Micrographs of Epidermal Protrusions and Unusual Fusion Sutures of Cutinase-Expressing Arabidopsis Plants. polysaccharides deposited in the fusion zones may be very large, as shown in Figure 9F.

\section{Cutinase-Expressing Plants Have No Impairment in Wax Deposition}

The severe structural changes of the cuticle of cutinaseexpressing Arabidopsis plants made a study of the waxes particularly interesting, even though cutinase-expressing plants showed no alterations in the reflectance of the organs. In Arabidopsis stems, epicuticular waxes are deposited in crystals, the form of which depends on the composition of the wax (Koornneef et al., 1989). Stems of cutinase plants with strong fusion phenotypes, the plants from which the most drastic changes were to be expected, were analyzed by scanning electron microscopy. Mainly, the crystal forms visualized in the epicuticular wax layers of cutinase-expressing plants and wild-type plants were identical (data not shown).

In Arabidopsis leaves, epicuticular wax is deposited in an amorphous form and therefore cannot be analyzed by scanning electron microscopy ( enks et al., 1995). Leaf surface waxes solubilized by chloroform extraction were analyzed by thin-layer chromatography and gas chromatographymass spectrometry. The wax preparations of both control plants and cutinase-expressing plants with strong organ fusion phenotypes were separated into three major fractions-hydrocarbons, fatty alcohols, and fatty acids-and three unidentified fractions. The most abundant compounds detected by gas chromatography-mass spectrometry were the hydrocarbons heptacosane, nonacosane, and hentricosane. The primary fatty alcohols detected were 1-octacosanol, 1-triacontanol, and 1-dotricontanol, with 1-dotricontanol being the most abundant of this group of compounds. The fatty acids tetradecanoic $\left(C_{14}\right)$, hexadecanoic $\left(C_{16}\right)$, octadecanoic $\left(C_{18}\right)$, eicosanoic $\left(C_{20}\right)$, docosanoic $\left(C_{22}\right)$, tetracosanoic $\left(\mathrm{C}_{24}\right)$, hexacosanoic $\left(\mathrm{C}_{26}\right)$, and octacosanoic acid $\left(C_{28}\right)$ were detected. Also detected were $C_{18: 1}, C_{18: 2}$, and

(A) Epidermal protruding ridge (large arrows) in a bent stem segment and fusion between the stem and a leaf (arrowheads) at the distal side of the protrusion. $\mathrm{Bar}=500 \mu \mathrm{m}$.

(B) Specimen from (A) tilted and enlarged to visualize the two parallel protruding ridges (arrows) along the stem. Bar $=100 \mu \mathrm{m}$.

(C) The base of a filament similar to the filament shown in Figure $6 \mathrm{~A}$ that formed at an epidermal ridge (arrows) protruding along a stem. Of interest are the large cells in the protrusion (arrowheads). Bar = $50 \mu \mathrm{m}$.

(D) Organ fusion between two leaves, leading to breakage of the epidermis. At the wound site, mesophyll cells bulged out from the inside of the leaf (arrows). Large tube-like cells lay within the plane of the epidermis close to the suture (arrowheads). Bar $=100 \mu \mathrm{m}$. F, filament; L, leaf; S, stem; U, upper leaf. 

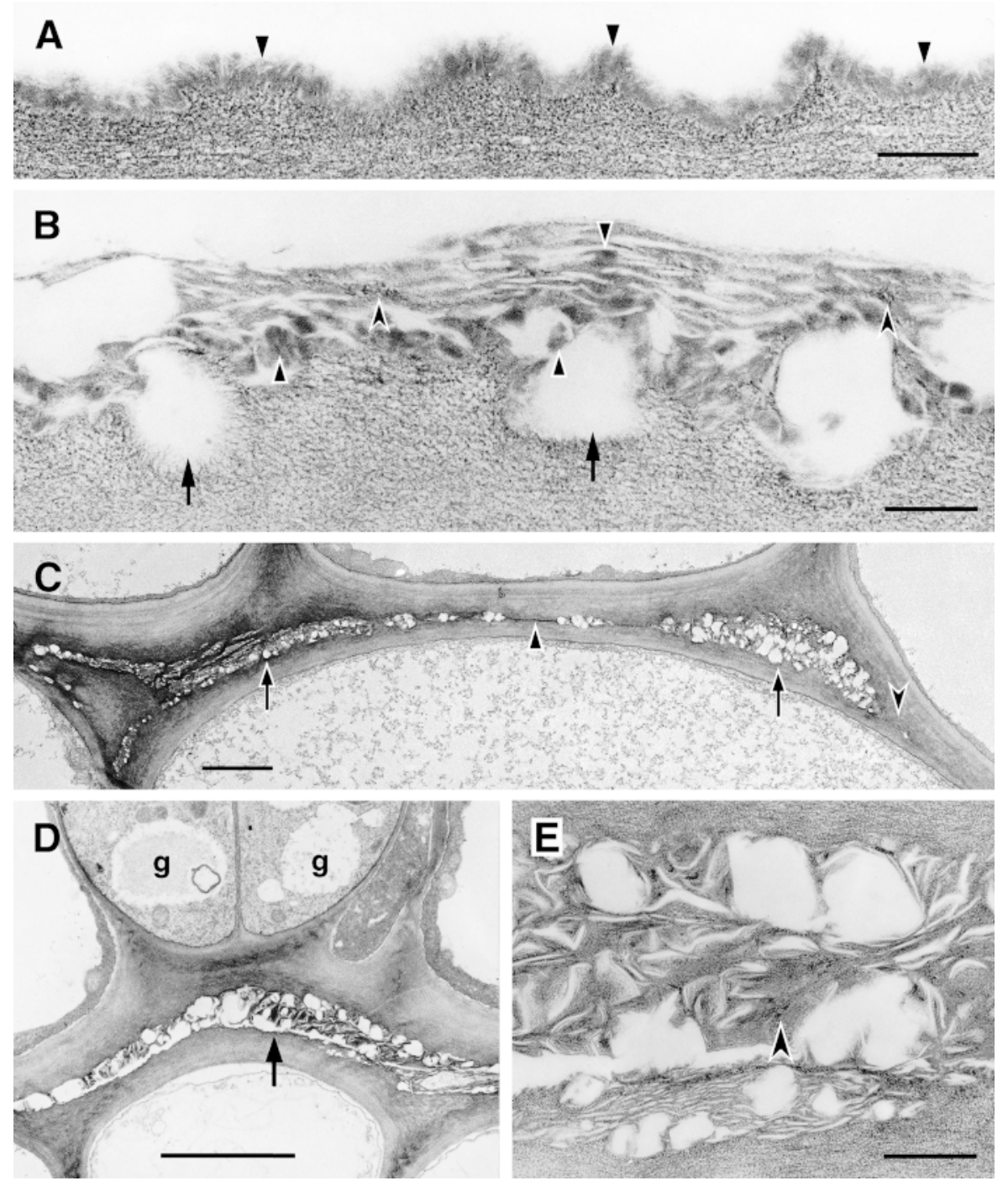

Figure 8. Ultrastructure of the Cuticle of the Stem Epidermis of Wild-Type and Cutinase-Expressing Arabidopsis Plants, and Organ Fusions between the Stems of a Transgenic Plant.

(A) Col-0/gl1. Outer wall of an epidermal cell with cuticle of uniform structure (arrowheads) overlying the cell wall polysaccharides. Bar $=200 \mathrm{~nm}$. (B) Cutinase-expressing Col-0/gl1. In contrast to the control, the contact zone between the cell wall polysaccharides and the cuticle was interrupted (arrows). Cuticular material accumulated in highly variable amounts, from apparently none to aggregates of mixed composition. Amorphous material of cuticular origin (solid arrowheads) was interspersed with polysaccharide microfibrils (concave arrowheads) in a loosely structured cuticle. Bar $=200 \mathrm{~nm}$.

(C) Cutinase-expressing Col-0/gl1. Fusion between two stems, overview. Apparently empty spaces surrounded by polysaccharidic cell wall materials characterize the fusion zone at most places (arrows). Areas containing small amounts of cuticular material can also be seen (solid arrowhead). At some places, the cuticle was interrupted and the cell walls of both epidermal cells came into direct contact (concave arrowhead). Bar $=2 \mu \mathrm{m}$.

(D) Cutinase-expressing Col-0/gl1. Fusion between two stems. Two stomatal guard cells (g) were present in fused epidermal cell layers. Apparently empty spaces surrounded by polysaccharidic cell wall materials characterized this fusion zone (arrow). Bar $=5 \mu \mathrm{m}$.

(E) Cutinase-expressing Col-0/gl1. Enlarged view of detail in (D). At this magnification, a large part of the materials in the fusion zone can be seen to have a fibrillar ultrastructure and to resemble cell wall polysaccharides (concave arrowhead). Waxy compounds were at least partially extracted during the dehydration and embedding procedures. Bar $=500 \mathrm{~nm}$. 

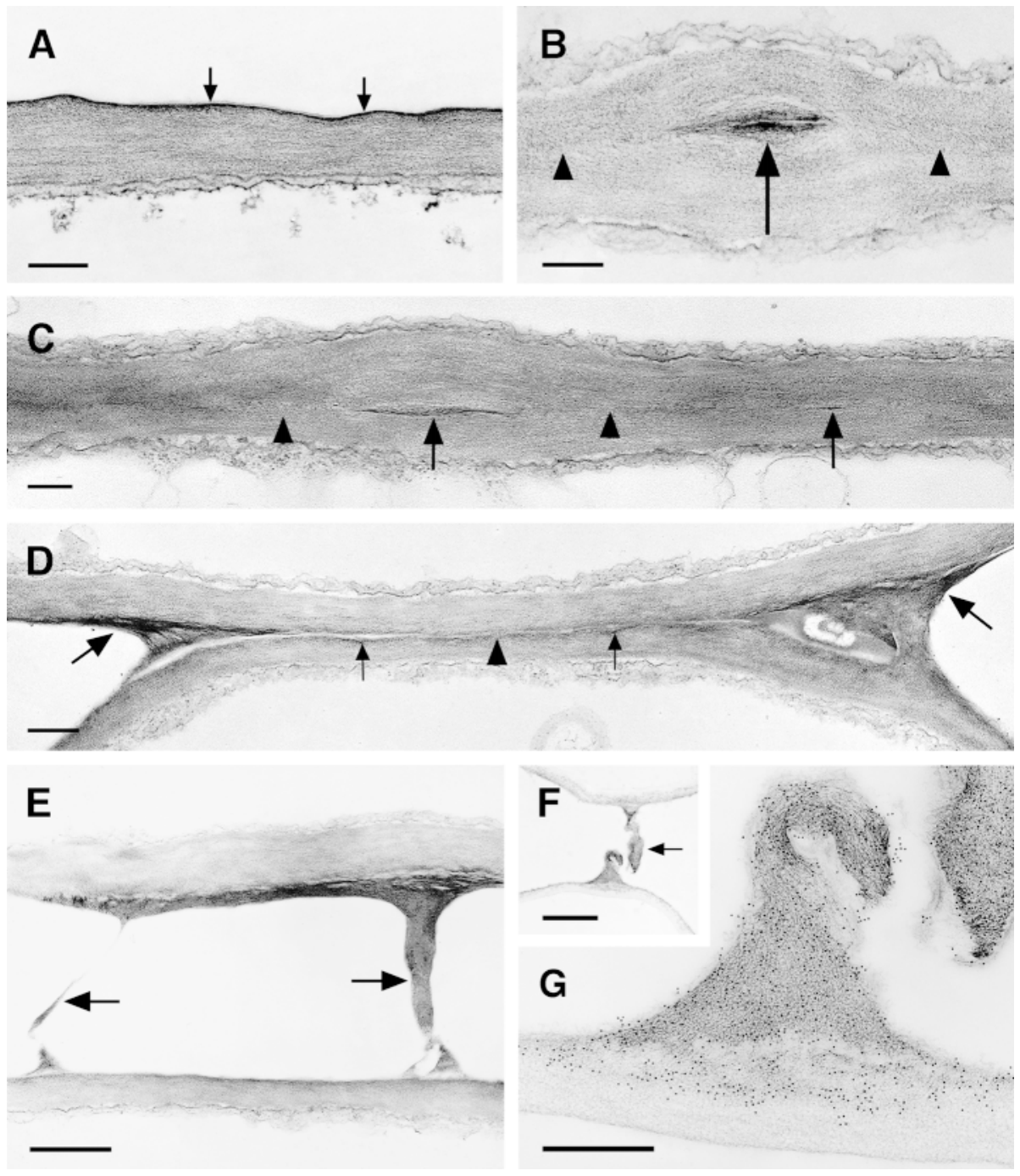

Figure 9. Ultrastructure of the Cuticle of the Leaf Epidermis, Structural Variations in the Fusion Zone between Leaves of Cutinase-Expressing Arabidopsis, and Identification of Pectic Polysaccharides as Essential Components of Organ Fusion.

(A) Col-0/gl1. A thin electron-dense cuticle (arrows) overlays the cell wall polysaccharides in leaves. Bar $=250 \mathrm{~nm}$.

(B) and (C) Cutinase-expressing Col-0/gl1. The fusion zone between leaves is characterized by stretches of a direct contact of the polysaccharides (arrowheads) of the two epidermal cells and the local occurrence of interspersed cuticular material (arrows). Tilting the specimen (C) in the regions of a direct contact of polysaccharides confirmed the absence of detectable amounts of cuticular material or any structural change at the position where both cell walls came into contact (arrowheads). Bars $=250 \mathrm{~nm}$.

(D) Cutinase-expressing Col-0/gl1. The fusion zone is characterized by stretches of small amounts of cuticular material (small arrows) that is partially missing (arrowhead). In contrast to (C), the position at which the cell walls of both epidermal cells came into contact was still visible. At the positions of the cell corners where the fusion was tearing apart, electron-dense polysaccharide material accumulated (large arrows). Bar $=500 \mathrm{~nm}$. (E) Stretched polysaccharide filaments (arrows) connecting two epidermal cells at points of high mechanical stress at the border of a fusion zone. Bar $=1 \mu \mathrm{m}$.

(F) and (G) A large polysaccharide filament in a fusion zone probably originated under mechanical stress.

(F) Overview of the region; the arrow indicates the polysaccharide filament. Bar $=2 \mu \mathrm{m}$.

(G) Immunolabeling of the polysaccharides involved in organ fusion by J IM 5 monoclonal antibodies, specific for pectin with low degrees of esterification. Bar $=500 \mathrm{~nm}$. 
$\mathrm{C}_{18: 3}$ fatty acids and $\beta$-sitosterol, which we considered to be contaminants from the membrane fractions of the plants. The epicuticular wax composition of leaves of Arabidopsis accession Col-0/gl1 plants was therefore similar to that of the leaves of Arabidopsis accessions Wassilewskija and Landsberg erecta (J enks et al., 1995). However, minor compounds such as some fatty acids, aldehydes, and secondary alcohols could not be detected reproducibly in these small-scale preparations. Interestingly, typical cutin monomers were also not detected in the wax preparations of cutinase-expressing plants, indicating that cutin monomers do not accumulate to high levels on the surface.

There were no real differences between control plants and cutinase-expressing plants with regard to the abundance of fatty acids and primary fatty alcohols or membrane contaminants. In contrast, the components of the hydrocarbon fraction were considerably more abundant in cutinase-expressing plants than in control plants, with heptacosane 4.5 times higher, nonacosane six times higher, and hentricosane six times higher. Similar results were obtained in two independent series of experiments and in analysis of two independent transgenic lines.

These results demonstrate that the epicuticular wax deposition is not impaired in cutinase-expressing plants. The greater amount of waxes rich in hydrocarbons might indicate a higher deposition of these particular waxes in cutinase-expressing plants. However, in view of the hyperpermeability of the cuticle of cutinase-expressing plants, as measured by protein leaching, chlorophyll leaching, and herbicide sensitivity (see above), hydrocarbons might also be more extractable in cutinase-expressing plants than in control plants. Such hydrocarbons could even originate in the intracuticular waxes, which may be more susceptible to chloroform extraction in plants that have a disrupted cuticle.

\section{DISCUSSION}

In wild-type Arabidopsis plants, the structure of the cuticle of stems and leaves is amorphous as reported for other Brassica species (Holloway, 1982; J effree, 1996), the cuticle of the stems being much thicker than that of the leaves. Cutinase-expressing plants have ultrastructural changes at the location of the cutin polymer, that is, at the outer extracellular matrix of the shoot epidermis, which results in a looser structure of the cuticle, which is sometimes totally missing. Although in this study the cutinase was expressed under the control of the CaMV 355 promoter, leading to expression of cutinase in almost all tissues, including the roots, ultrastructural changes were observed only in tissues having a cuticle. Therefore, the phenotypic changes observed in the transgenic plants probably result primarily from cutin degradation by the expressed enzyme and not from any lipase activity of the cutinase that has been detected in vitro (Kolattukudy, 1984). In the absence of cutin mutants and characterized cutinase genes in plants, the transgenic plants expressing a fungal cutinase therefore offer a means to examine the possible role of cutin in vivo.

In this study, cutinase-expressing Arabidopsis Col- 0 and Col-0/gl1 were investigated for several specific characteristic phenotypes, such as cuticle permeability and structure, pollen germination, and formation of postgenital organ fusions with consequences for the growth habit of the plant. For all of these characteristics, the strength of the phenotype correlated with the amount of cutinase expression. However, plants with very high cutinase activity $\left(>10 \times 10^{-4}\right.$ $\mathrm{mmol} \mathrm{mg}^{-1}$ of protein $\mathrm{min}^{-1}$ ) are also characterized by a general dwarfism, spontaneous death of primary shoots, and irregularly formed laminas of the leaves, with concavities, convexities, and occasional necrotic margins. These phenotypes were regarded as not very specific for cutinaseexpressing plants and were not investigated in detail.

\section{Cutin Is Important for Cuticle Function as a Permeability Barrier}

Early studies on isolated cuticular layers showed that treatment with cutinase led to increased permeability and decreased strength of the cuticle (Baker et al., 1982). More recent studies on reconstituted wax layers, however, have indicated that waxes form the major transport-limiting barrier (Riederer and Schreiber, 1995; Schreiber et al., 1996), primarily because of their highly ordered structure (Reynhard and Riederer, 1991, 1994). Analyses of the properties of the cuticle of cutinase-expressing plants indicate that the presence of an intact cutin layer is important as a permeability barrier. The results obtained in this study suggest that the high permeability of the cuticle in cutinaseexpressing plants is a result of the altered structure of the cutin itself, because the cuticle forms a discontinuous layer in cutinase-expressing plants. Nevertheless, the effect may also be indirect in that the altered structure of the cutin does not support normal deposition of intracuticular waxes. Examining epicuticular waxes by several different methods indicated no major changes in their amount, composition, or structure in cutinase-expressing plants, except perhaps for an increase in hydrocarbons. However, whether the greater amounts of hydrocarbons extracted from cutinase-expressing plants could also originate from the intracuticular waxes is unclear. Interestingly, the plants were able to grow under standard humidity conditions $(60 \%)$ and were not very sensitive to decreased humidity during handling. This indicates a major role for waxes as a humidity barrier.

\section{Cutin Is Involved in Preventing Ectopic Germination of Pollen}

Germination of Arabidopsis and Brassica pollen on mature leaves of cutinase-expressing plants is a specific 
demonstration of the altered structure of the cuticle and supports the hypothesis that pollen germination of Arabidopsis and Brassica occurs when the cuticle is absent or very thin (Wolters-Arts et al., 1998). Perhaps leaf surfaces with a thin cutin layer supply the pollen with a better microclimate or substances for hydration and germination, particularly when lipids are present.

Pollen from dry-stigma plants, such as nasturtium and B. rapa, a close relative of Arabidopsis, has been found to have cutinase in the pollen coat (Maiti et al., 1979; Hiscock et al., 1994). Apparently, therefore, the amount of cutinase in Arabidopsis pollen is insufficient for penetration of thick, mature cutin layers; only when the cuticle is particularly thin, as for example on the cuticle of cutinase-expressing plants, is the pollen able to penetrate. However, it is also possible that the biological significance of this observation has not been fully understood. Germination of pollen from Arabidopsis and related species on shoot organs has also been described for the fdh mutant (Lolle and Cheung, 1993) and other organ fusion mutants of Arabidopsis (Lolle et al., 1998); the relation of these mutants to cutinase-expressing plants is discussed in detail below.

\section{Loosened Cuticle Structure Allows Interaction of Pectic Polysaccharides, Leading to Organ Fusions}

In cutinase-expressing plants, the unresponsiveness of epidermal cells to contact is severely impaired. Contacting organs undergo postgenital fusions early in development, when cells are still expanding. Fusions may occur when epidermal layers of different organs are closely appressed and waxes might not yet have accumulated to large amounts; at such times, the cell walls underlying incomplete or disrupted cuticles come into contact and are able to copolymerize. The cell wall underneath the cuticle is rich in pectin () effree, 1996). In this study, pectin, whether methylated or unmethylated, was also found to be a component of the fusion zones of cutinase-expressing Arabidopsis. However, other polysaccharides probably also participate in the fusion, as shown in the ad1 mutant (Sinha and Lynch, 1998).

Pectic polysaccharides have been discussed in several systems as components that are important for cell adhesion (Rhee and Somerville, 1998), and pectinase activity is induced during cell separation, for example, during fruit ripening (Stephenson and Hawes, 1994; Klein et al., 1995). Unesterified pectin reportedly is correlated with cell separation, being present in cell walls proximal to intercellular space in carrot roots, for example (Knox et al., 1990). Interestingly, both methylated and unmethylated pectin has been found in the fusions of cutinase-expressing Arabidopsis plants.

In addition, the point of fusion between organs growing apart from each other contains large quantities of pectic polysaccharide material. This may indicate that pectic polysaccharide biosynthesis has been induced to cope with mechanical stress between fused cell walls.

\section{Organ Fusion in Arabidopsis and Maize}

The organ fusions of cutinase-expressing plants are similar to the organ fusions observed in several mutants of Arabidopsis or maize (Lolle et al., 1992, 1998; J enks et al., 1996; Sinha and Lynch, 1998) in that the epidermal layers fuse postgenitally only through their cell walls and no dedifferentiation occurs, as in postgenital carpel fusion of Catharanthus roseus (Verbeke, 1992). Several types of mutants showing postgenital organ fusion seem to exist. First, there are mutants with a reduction in the epicuticular wax deposition, such as the Arabidopsis wax mutants wax1, cer10, cer13, and the maize adh1 mutant ( enks et al., 1996; Lolle et al., 1998; Sinha and Lynch, 1998). Second, there are plants in which organ fusion is not correlated with a reduction in epicuticular waxes, such as the cutinase-expressing transgenic plants, the fdh mutant, and several other floral adhesion mutants (Lolle et al., 1998). However, a detailed analysis of the amount, structure, or composition of the epicuticular waxes has not been performed for either the fdh mutant (Lolle et al., 1992, 1997) or the other floral adhesion mutants. Further, the primary cause of organ fusion has not been exactly determined in mutants that show both a reduced epicuticular wax load and organ fusion.

In the fdh mutant, an electron-dense layer of lipophilic material is present in the fused regions (Lolle et al., 1992). However, some alterations in the cell wall-bound lipid fraction of the fdh mutant have indicated that the cell wall or the cuticle might be altered (Lolle et al., 1997). For other adhesion mutants without obvious changes in the epicuticular wax layer, no information on either cuticle structure or the composition of the extracellular matrix has been reported (Lolle et al., 1998). The similarity of the fdh gene product to fatty acid elongases suggests that the biosynthesis of a very long chain fatty acid may be impaired in the fdh mutant (Yephremov et al., 1999; Pruitt et al., 2000). The exact biochemical function of FDH protein, however, remains to be elucidated.

In contrast, cutinase-expressing plants have visible changes in the cuticle structure, including the fusion sutures. Electron-dense structures were only rarely detected in fusion zones (of cutinase-expressing plants) and are thought to be remnants of incomplete cuticle formation, in accordance with the function of the transgene. Therefore, cutinaseexpressing plants present clear experimental evidence that the structure of the cuticle and the presence of cutin are relevant to prevent organ fusion.

Cutinase-expressing plants share phenotypes similar to those of the fdh mutant for several commonly analyzed parameters, including organ fusions, chlorophyll leaching, and pollen germination. Cutinase-expressing plants also show a clear change in the cuticle ultrastructure, which adds new support to the hypothesis that the fdh mutant may have a defect in the cuticle, and that other mutants that share all three of these main characteristics, such as the thunderhead mutant of Arabidopsis, may also be cuticle mutants (Lolle et 
al., 1998). However, because a significantly reduced number of trichomes has recently been observed in the fdh mutant in Col- 0 background in comparison to Col-0 control plants (Yephremov et al., 1999)-which was not obvious in the cutinase-expressing Col- 0 studied here-it is possible that the fdh mutants may have a more complex phenotype that possibly includes cuticle changes. The possibility that several primary causes may lead to postgenital organ fusions also cannot be excluded.

A properly formed lipophilic cuticular layer may keep the organs separate and thus prevent organ fusion. Perhaps the cuticle also acts to seal the epidermis from the exchange of cell-to-cell communication signals. Therefore, the altered properties of the cuticle in cutinase-expressing plants might allow an exchange of signals that normally does not occur, an exchange that leads to organ fusion. An exchange of signals found during postgenital carpel fusion in C. roseus (Verbeke, 1992) has also been postulated for organ fusion mutants of Arabidopsis (Lolle and Pruitt, 1999). In addition, cutin monomers might act as signals in plant development, having been shown to be perceived by plant cells in such a way as to result in alkalinization of the culture medium (Schweizer et al., 1996a). Cutin monomers possibly also act as elicitors of plant defense responses, because application of cutin monomers leads to resistance to pathogens in barley and rice (Namai et al., 1993; Schweizer et al., 1994, 1996b) or to $\mathrm{H}_{2} \mathrm{O}_{2}$ production in cucumber hypocotyls (Fauth et al., 1998; Kauss et al., 1999).

\section{Mechanical Stress Leads to Changes in Organ Morphology and Epidermal Development}

The strong fusion phenotype allows us to study the reaction of plants, particularly their epidermal layer, to mechanical stress. The point application of mechanical stress by organ fusion can lead to shape alterations in which all cell layers are involved, but it can also lead to filaments formed mainly from epidermal cells. The formation of epidermal filaments shows that the epidermal cell layer may react independently of the other tissues, utilizing cell proliferation to cope with mechanical stress. A different reaction of the epidermis is seen when only the epidermal layer folds upward in a twisted stem, forming protruding ridges. The presence of cells of irregular size and form in the fusion zones as well as the formation of protrusions and multilayered epidermal cell layer segments by periclinal divisions of the epidermal cells indicate that some epidermal cells have lost their orientation or epidermal identity (or both). Periclinal divisions are very unusual for the epidermal cell layer, which is derived from the outermost cell layer of the shoot meristem (L1) during development (Szymkowiak and Sussex, 1996). Apparently, epidermal cells need information from their local environment, such as from underlying cell layers or from the cuticle, to maintain all characteristics of epidermal cells, including anticlinal cell divisions resulting in a unicellular layer. The im- portance of the cell wall for the determination of cell polarity and plane of division has been demonstrated in Fucus embryos (Quadrano and Shaw, 1997). A fusion phenotype with disturbed epidermal differentiation and epidermal bridges between organs has been found in the crinkly4 mutant of maize (Becraft et al., 1996). Whether the epidermal cell bridges occur only at points of mechanical stress has not been described. The gene causing the mutant phenotype encodes for a tumor necrosis factor-like receptor kinase; the mechanistic relationship between the mutated gene and the phenotype remains to be discovered.

The results presented in this study demonstrate that degradation of extracellular matrix polymers in vivo may be a valid approach for studying the biological significance of cell wall polymers in general. Cutinase expression reveals the important role of cutin and demonstrates in vivo the impact of a destroyed cuticle on the plant. The physical properties of the cuticle not only affect the quality of the interface between the plant and its external environment but also play an important role in the normal development of the plant. Further studies on cutinase-expressing plants should give insight into the significance of cutin for other important functions of the epidermis, such as defense against pathogens and insects or other abiotic stresses, and enable us to study specific aspects of organ development.

\section{METHODS}

\section{Bacteria, Plants, and Growth Conditions}

For transformation of plants, Agrobacterium tumefaciens GV3101/ pMP90 (Koncz and Schell, 1986) was used. Arabidopsis thaliana accession Columbia (Col-0) as well as Col-0/glabrous1 (gl1) were obtained from Chris Somerville (Carnegie Institution, Stanford, CA). Plants were grown at 20 to $22^{\circ} \mathrm{C}$, in $60 \%$ humidity, with a 12 -hr-light/ 12 -hr-dark cycle. Under sterile conditions, plants were grown on $\mathrm{Mu}$ rashige and Skoog medium (Sigma) containing $10 \mathrm{~g} / \mathrm{L}$ sucrose, $8 \mathrm{~g} / \mathrm{L}$ Bacto agar (Difco), and when applicable, $50 \mu \mathrm{g} / \mathrm{mL}$ kanamycin; after 2 weeks, the plants were transferred to soil and slowly adapted to growth in lower humidity.

\section{Generation of Cutinase-Expressing Plants}

The coding region of the mature cutinase of Fusarium solani $\mathrm{fp}$ pisi (Soliday et al., 1984) was amplified by polymerase chain reaction (PCR) from the construct in pBluescript KS - (Stratagene, La J olla, CA) designated pBSKS(-):LTPP:CUT (P. Kolattukudy, personal communication) by the Vent ${ }_{R}$ DNA Polymerase (New England $\mathrm{Bi}$ olabs, Beverly, MA) using the oligonucleotides 5'-CUT (5'TGCTAGCGCTGGTAGAACAACTCG-3'; Nhel site underlined) and 3'-CUT (5'-TAGGTACCTCAAGCAGAACCACG-3'; Kpnl site underlined). The $0.6-\mathrm{kb}$ band was digested with Nhel and $\mathrm{Kpnl}$ and cloned behind the signal sequence from the chitinase A from tobacco (Shinshi et al., 1990) by digesting the plasmid pMRE7066::SS::GFP (MRE for metallothionine-responsive element [Mett et al., 1993]; SS for signal 
sequence; and GFP for green fluorescent protein) (P. Sieber and C. Nawrath, data not shown), resulting in pPMB 7066:SS:CUT. The cohesive ends of the $0.7-\mathrm{kb}$ signal sequence and the cutinase fusion obtained by digesting pPMB 7066::SS::CUT with Sacl-Xbal were filled in with the T4 DNA polymerase (New England Biolabs) and cloned into pART7 (Glaeve, 1992) that had been digested with Smal. A plasmid having the SS::cutinase fusion cloned in the correct orientation behind the cauliflower mosaic virus (CaMV) $35 \mathrm{~S}$ promoter was digested with Notl, and the 3.1-kb fragment was cloned into PART27 (Glaeve, 1992). The construct called p35S::SS::Cut was transformed in the Agrobacterium strain GV3101/pM P90 (Koncz and Schell, 1986). Arabidopsis accession Col- 0 and $\mathrm{Col}-0 / \mathrm{gl} 1$ were transformed by the vacuum infiltration method (Bechtold et al., 1993). Seven independent transformants of Arabidopsis $\mathrm{Col}-0$ and 13 independent transformants of Arabidopsis Col-0/gl1 were analyzed.

\section{Cutinase Assays}

To obtain crude extracts, leaf material was extracted in a protein extraction buffer $(100 \mathrm{mM}$ Tris- $\mathrm{HCl}, \mathrm{pH} 7.3,5 \mathrm{mM}$ EDTA, and 0.05\% $\beta$-mercaptoethanaol) and cleared by centrifugation. To prepare intercellular wash fluids, $100 \mathrm{mg}$ of leaf material was submerged in 4 or 5 $\mathrm{mL}$ of protein extraction buffer and vacuum infiltrated. After being blotted on paper towel, the infiltrated leaves were placed into a 10$\mathrm{mL}$ syringe and centrifuged for $20 \mathrm{~min}$ at $472 \mathrm{~g}$, after which the fluid was collected (Keefe et al., 1990). To measure the diffusion of apoplastic fluids into solution, $100 \mathrm{mg}$ of leaf material was submerged in $2.5 \mathrm{~mL}$ of protein extraction buffer and incubated at $4^{\circ} \mathrm{C}$ with gentle agitation. Protein concentrations were determined using a protein assay from Bio-Rad (Watford, UK). Cutinase activity was measured spectrophotometrically at $405 \mathrm{~nm}$ by hydrolyzing the substrate $p$-nitrophenyl butyrate to $p$-nitrophenol. Reactions were performed at $30^{\circ} \mathrm{C}$ in a $3-\mathrm{mL}$ volume containing $2 \mathrm{~mL}$ of substrate mix $(100 \mathrm{mM}$ Tris- $\mathrm{HCl}, \mathrm{pH} 7.3,0.03 \%$ Triton $\mathrm{X}-100$, and $0.01 \% \mathrm{p}$-nitrophenol butyrate [Fluka, Buchs, Switzerland] kept on ice in the dark), various amounts of plant extract, and $100 \mathrm{mM}$ Tris- $\mathrm{HCl}, \mathrm{pH} 7.3$ (Dickmann et al., 1982; with modifications by K. Gindro, personal communication). The absorptivity of $\mathrm{p}$-nitrophenol at $405 \mathrm{~nm}$ was $3.89 \mu \mathrm{mol} \times \mathrm{cm}^{3}(\mathrm{~K}$. Gindro, personal communication).

\section{Chlorophyll Extraction and Quantification}

Leaves were carefully cut at the petiole and, after their fresh weight was determined, immersed in $30 \mathrm{~mL}$ of $80 \%$ ethanol. Chlorophyll was extracted in the dark at room temperature with gentle agitation. Aliquots were removed at 2, 5, 10, 20, 30, 40, 50,60, and 120 min after immersion. Chlorophyll content was determined by measuring absorbance at 664 and $647 \mathrm{~nm}$ (Hiscox and Israelstam, 1979). The micromolar concentration of total chlorophyll per gram of fresh weight of tissue was calculated from the equation in which total micromoles of chlorophyll $=7.93\left(A_{664 n m}\right)+19.53\left(A_{647} \mathrm{~nm}\right)$.

\section{Application of Chemicals}

Roundup Ultra (Monsanto, St. Louis, MO) was sprayed on 2- to 3-week-old plants ( $1 \mathrm{~mL}$ per 10 -cm-diameter pot) at concentrations between $10 \mu \mathrm{L} / \mathrm{mL}$ and $3.3 \times 10^{-4} \mu \mathrm{L} / \mathrm{mL}$ in water. Plant reactions were monitored for 2 weeks.

\section{Pollen Germination Assay}

Pollen grains from anthers of freshly opened flowers of Arabidopsis accession Col-0, Brassica rapa, Nicotiana tabacum, and a petunia hybrid $(P$. axillaris $\times P$. violaceae) were gently applied to leaves (200 to 1000 pollen grains $\mathrm{cm}^{-2}$ ). At 16 to $25 \mathrm{hr}$ after pollen application, specimens were prepared for light microscopy.

\section{Transmission Electron Microscopy}

Small pieces of Arabidopsis stems and leaves and of fused organs of transgenic plants were fixed with glutaraldehyde $(2 \%)$ in sodium cacodylate $(0.05 \mathrm{M}, \mathrm{pH} 7.2)$ for $2 \mathrm{hr}$ at room temperature and postfixed with $\mathrm{OsO}_{4}(1 \%)$ in sodium cacodylate at $4^{\circ} \mathrm{C}$ overnight. After dehydration with acetone at room temperature, the material was embedded in Spurr's standard epoxy resin and the resin was polymerized at $70^{\circ} \mathrm{C}$ for $18 \mathrm{hr}$. Thin sections were stained with uranyl acetate $(2 \%$ in $50 \%$ acetone) and alkaline lead citrate (Reynolds, 1963) for $0.5 \mathrm{hr}$ each. For immunolabeling, materials were fixed with a mixture of glutaraldehyde $(1.5 \%)$ and paraformaldehyde $(2 \%)$ in sodium potassium phosphate buffer $(0.066 \mathrm{M}, \mathrm{pH} 7.4)$. After dehydration with ethanol at room temperature, the material was embedded in an acrylic resin ( $L R$ White Hard; London Resin, Reading, UK). The resin was polymerized with UV light in a CS-Auto cryosubstitution apparatus (Leica, Zürich, Switzerland) at $-15^{\circ} \mathrm{C}$ for $24 \mathrm{hr}$. The temperature was then raised to $20^{\circ} \mathrm{C}$ at $10^{\circ} \mathrm{C}$ per $\mathrm{hr}$, and the polymerization was continued for another $42 \mathrm{hr}$. Micrographs were taken with a Philips CM 100 BIOTWIN electron microscope (Philips Electron Optics, Eindhoven, The Netherlands).

\section{Immunogold Labeling}

J IM 5, J IM 7, and J IM 13 monoclonal antibodies were obtained from K. Roberts (V ohn Innes Centre, Norwich, UK). J IM 5 recognizes epitopes of unesterified pectin, and J IM 7 recognizes methyl-esterified pectin (Knox et al., 1990). J IMI3 recognizes the carbohydrate part of arabinogalactan proteins (Knox et al., 1991). Ultrathin sections of silver to gold interference color were harvested on Formvar- and carboncoated nickel grids (Plano Gmbh, Wetzlar, Germany); treated for 15 min with $50-\mu L$ drops of a mixture of glycine $(20 \mathrm{mM})$, lysine $(20 \mathrm{mM})$, and $\mathrm{NH}_{4} \mathrm{Cl}(20 \mathrm{mM})$ to block aldehydes; and treated for $15 \mathrm{~min}$ with $1.25 \%$ goat serum (GS; British Biocell International, Cardiff, UK) in Tris-buffered saline (TBS: $20 \mathrm{mM}$ Tris, $\mathrm{pH} \mathrm{7.5}$, and $\mathrm{NaCl}$ at either $0.05,0.15$, or $0.5 \mathrm{M}$ ) to inhibit nonspecific adsorption of antibodies. Subsequently, sections were incubated with the primary antibody (diluted 1:10 with TBS-GS) for $2 \mathrm{hr}$ at room temperature in a humid chamber, washed three times for $10 \mathrm{~min}$ in TBS with gentle shaking, incubated for $2 \mathrm{hr}$ at room temperature with the secondary antibody (10-nm particles of gold-labeled goat anti-rat IgG; British BioCell), and diluted with TBS containing $0.5 \%(\mathrm{w} / \mathrm{v})$ Tween (TBST)-GS to an optical density of 0.1 (at $525 \mathrm{~nm}$ ). The sections were then washed several times with TBST and finally with distilled water before air drying overnight. Thin sections were stained for 5 and 1 min with the uranyl acetate and alkaline lead citrate reagents described above, respectively, followed by a short rinse in distilled water. J IM 13 was used as a control. No substantial labeling was observed with this antibody in the epidermis of transgenic and control Arabidopsis plants. Labeling with J IM 5 is salt sensitive and was reduced to background levels with $0.5 \mathrm{M} \mathrm{NaCl}$ in TBS-GS. 


\section{Scanning Electron Microscopy}

To visualize organ fusions, small pieces of tissue were fixed as for transmission electron microscopy and partially dehydrated in $70 \%$ acetone at room temperature. After critical point drying in $\mathrm{CO}_{2}$, the specimens were sputtered with gold and observed in a Hitachi S-4000 scanning electron microscope (Hitachi Scientific Instruments, Tokyo, J apan).

To visualize the structure of the wax crystals, small pieces of tissue were excised from stems and leaves and then frozen in nitrogen slush (a mixture of frozen and liquid nitrogen at $-210^{\circ} \mathrm{C}$ ) in an $\mathrm{EM}$ SCOPE SP 200A system (Bio-Rad) for low-temperature scanning electron microscopy. After a short sublimation of ice formed at the specimen surface, the specimen was sputtered with gold and observed in a Hitachi S-4000, modified for low-temperature scanning electron microscopy.

\section{Light Microscopy}

For semithin sections, material was fixed as for transmission electron microscopy, and semithin sections were stained with methylene blue-azure A and safranin 0 according to Warmke and Lee (1976). After pollen application, leaves were fixed for $3 \mathrm{hr}$ in a solution of $3.7 \%$ formaldehyde, $5 \%$ acetic acid, and $50 \%$ ethanol, and then transferred to $70 \%$ ethanol. After incubation at $4^{\circ} \mathrm{C}$ for at least 1 day, the specimens were rinsed with $25 \%$ ethanol and then incubated in $4 \mathrm{M} \mathrm{NaOH}$ for $1 \mathrm{hr}$. After being washed in $65 \mathrm{mM}$ sodium phosphate buffer, specimens were incubated (at least $30 \mathrm{~min}$ ) and mounted in decolorized aniline blue $(0.05 \%$ in $65 \mathrm{mM}$ sodium phosphate buffer, pH 8.5 to 9) (Lolle and Cheung, 1993). The callose in the pollen tubes was visualized with a Leitz Dialux epifluorescence microscope (Leica Microscopy and Systems $\mathrm{GmbH}$, Wetzlar, Germany), using a filter for UV excitation at 340 to $380 \mathrm{~nm}$. Autofluorescence of pollen grains was visualized with blue light excitation at 450 to $490 \mathrm{~nm}$.

\section{Wax Analysis}

For thin-layer chromatography, the chloroform-soluble surface waxes were extracted from 6 -week-old plants by dipping $0.5 \mathrm{~g}$ of leaves in $8 \mathrm{~mL}$ of chloroform for $30 \mathrm{sec}$. Extracts were evaporated to dryness under vacuum and redissolved in $25 \mu \mathrm{L}$ of chloroform, which was then applied to a Silica Gel 60 TLC aluminum sheet (Merck, Darmstadt, Germany). The thin-layer chromatography was performed with a mobile phase of $5 \%$ ethyl ether and $1 \%$ formic acid in hexane. Separated components were detected by spraying the plate with $5 \%$ potassium bichromate in $50 \%$ sulfuric acid, followed by incubation for $0.5 \mathrm{hr}$ at $180^{\circ} \mathrm{C}$. For standards, surface waxes from B. oleracea and pure compounds were used.

For analyses by gas chromatography-mass spectrometry, the surface wax extracts were prepared as described above and then derivatized with an excess of $\mathrm{N}, \mathrm{O}$-bis(trimethylsilyl)trifluoroacetamide (Fluka, Buchs, Switzerland) containing 1\% trimethylchlorosilane, according to the manufacturer's directions. Between 100 and $1000 \mathrm{ng}$ of pentadecanoic acid was added as internal standard. The samples were then evaporated to dryness, taken up in hexane for analysis, and analyzed on a $25 \mathrm{~m} \times 0.2 \mathrm{~mm}$ HP-5MS capillary column (HewlettPackard, Palo Alto, CA) fitted to a Hewlett-Packard 6890 gas chromatograph that was connected to a Hewlett-Packard 5973 mass spectrometer. The carrier gas was helium, and the separations were programmed with an initial temperature of $70^{\circ} \mathrm{C}$ for $10 \mathrm{~min}$, increasing to $320^{\circ} \mathrm{C}$ at $6^{\circ} \mathrm{C} \mathrm{min}^{-1}$. Mass spectra were measured over the range 50 to 550 atomic mass units. Compounds were identified by comparing the spectra obtained with those of authentic compounds or by analogy. Approximately $10 \%$ of the total integrals corresponded to unidentified compounds. The quantitative analysis was based on total-ion chromatograms. Variations in quantity by less than a factor of two were seen as not significant.

\section{ACKNOWLEDGMENTS}

This work was supported by the EMBO and Novartis Foundations (fellowships to C.N.), the Swiss National Foundation (Grant Nos. 3134098 and 31-55662.98 to J.-P.M. and 31-49305.96 to U.R.), and the National Science Foundation (Grant No. IBN-9816868 to P.K.). We gratefully acknowledge Dr. Paul Reynolds for making the coppercontrollable gene expression system available to us and Dr. Keith Roberts for supplying us with the J IM 5, J IM 7, and J IM 13 antibodies. We thank Urs J auch for performing the scanning electron microscopy and Feyrouz Ounnais for her practical contributions. In addition, we thank Drs. Paul Knox and J ean-Marc Neuhaus as well as Katia Gindro for helpful discussions and Drs. Andrew Fleming, Yves Poirier, and Kay Schneitz for critical reading of the manuscript.

Received November 19, 1999; accepted March 10, 2000.

\section{REFERENCES}

Baker, C.J ., McCormick, S.L., and Batemann, D.F. (1982). Effects of purified cutin esterase upon the permeability and mechanical strength of cutin membranes. Phytopathology 72, 420-423.

Baker, E.A. (1982). Chemistry and morphology of plant epicuticular waxes. In The Plant Cuticle, D.F. Cutler, K.L. Alvin, and C.E. Price, eds (London: Academic Press), pp. 139-162.

Bechtold, N., Ellis, J ., and Pelletier, G. (1993). In planta Agrobacterium-mediated gene transfer by infiltration of adult Arabidopsis thaliana plants. C. R. Acad. Sci. 316, 1194-1199.

Becraft, P.W., Stinard, P.S., and McCarty, D.R. (1996). CRINKLY4: A TNKR-like receptor kinase involved in epidermal maize differentiation. Science 273, 1406-1409.

Deising, H., Nicholson, R.L., Haug, M., Howard, R.J ., and Mendgen, K. (1992). Adhesion pad formation and the involvement of cutinase and esterases in the attachment of uredospores to the host cuticle. Plant Cell 4, 1101-1111.

Dickmann, M.B., Patil, S.S., and Kolattukudy, P.E. (1982). Purification, characterization and role in infection of an extracellular cutinolytic enzyme from Colletotrichum gloeosporioides Penz. on Carica papaya L. Physiol. Plant Pathol. 20, 333-347.

Fauth, M., Schweizer, P., Buchala, A., Markstädter, C., Riederer, M., Kato, T., and Kauss, H. (1998). Cutin monomers and surface wax constituents elicit $\mathrm{H}_{2} \mathrm{O}_{2}$ in conditioned cucumber hypocotyl segments and enhance the activity of other $\mathrm{H}_{2} \mathrm{O}_{2}$ elicitors. Plant Physiol. 117, 1373-1380. 
Francis, S.A., Dewey, F.M., and Gurr, S.J . (1996). The role of cutinase in germline development and infection by Erysiphe graminis f. sp. hordei. Physiol. Mol. Plant Pathol. 49, 201-211.

Glaeve, A.P. (1992). A versatile binary vector system with T-DNA organisational structure conductive to efficient integration of cloned DNA into the genome. Plant Mol. Biol. 20, 1203-1207.

Hannoufa, A., McNevin, J .-P., and Lemieux, B. (1993). Epicuticular waxes of eceriferum mutants of Arabidopsis thaliana. Phytochemistry $33,851-855$.

Heide-J ørgensen, H.S. (1991). Cuticle development and ultrastructure-Evidence for a procuticle of high osmium affinity. Planta 183, 511-519.

Hiscock, S.J., Dewey, F.M., Coleman, J.O.D., and Dickinson, H.G. (1994). Identification and localization of a cutinase in the pollen of Brassica napus L. Planta 193, 377-384

Hiscox, J .D., and Israelstam, G.F. (1979). A method for the extraction of chlorophyll from leaf tissue without maceration. Can. J. Bot. 57, 1332-1334.

Hoffmann-Benning, S., and Kende, H. (1994). Cuticle biosynthesis in rapidly growing internodes of deepwater rice. Plant Physiol. 104, 719-723.

Holloway, P.J . (1982). Structure and histochemistry of plant cuticular membranes: An overview. In The Plant Cuticle, D.F. Cutler, K.L. Alvin, and C.E. Price, eds (London: Academic Press), pp. 1-32.

Hülskamp, M., Kopczak, S.D., Horejsi, T.F., Kihl, B.K., and Pruitt, R.E. (1995). Identification of genes required for pollen-stigma recognition in Arabidopsis thaliana. Plant J . 8, 703-714.

J effree, C.E. (1996). Structure and ontogeny of plant cuticles. In Plant Cuticles: An Integrated Functional Approach, G. Kerstiens, ed (Oxford, UK: BIOS Scientific Publishers), pp. 33-82.

J enks, M.A., Tuttle, H.A., Eigenbrode, S.D., and Feldmann, K.A. (1995). Leaf epicuticular waxes of the eceriferum mutants in Arabidopsis. Plant Physiol. 108, 369-377.

J enks, M.A., Rashotte, A.M., Tuttle, H.A., and Feldmann, K.A. (1996). Mutants in Arabidopsis thaliana altered in epicuticular wax and leaf morphology. Plant Physiol. 110, 377-385.

Kauss, H., Fauth, M., Merten, A., and J eblick, W. (1999). Cucumber hypocotyls respond to cutin monomers via both an inducible and a constitutive $\mathrm{H}_{2} \mathrm{O}_{2}$-generating system. Plant Physiol. 120, $1175-1182$.

Keefe, D., Hinz, U., and Meins, F., J r. (1990). The effect of ethylene on the cell-type-specific and intracellular localization of $\beta$-1,3-glucanase and chitinase in tobacco leaves. Planta 182, 43-51.

Kerstiens, G., ed (1996a). Plant Cuticles: An Integrated Functional Approach. (Oxford, UK: BIOS Scientific Publishers).

Kerstiens, G. (1996b). Signalling across the divide: A wider perspective of cuticular structure-function relationships. Trends Plant Sci. 1, 125-129.

Klein, J .D., Hanzon, J ., Irwin, P.L., Shalom, N.B., and Lurie, S. (1995). Pectin esterase activity and pectin methyl esterification in heated golden delicious apples. Phytochemistry 39, 491-494.

Knox, J .P., Linstead, P.J ., King, J ., Cooper, C., and Roberts, K. (1990). Pectin esterification is spatially regulated both within cell walls and between developing tissues of root apices. Planta 181, 512-521.
Knox, J .P., Linstead, P.J ., Peart, J ., Cooper, C., and Roberts, K. (1991). Developmentally regulated epitopes of cell surface arabinogalactan proteins and their relation to root tissue pattern formation. Plant J . 1, 317-326.

Kolattukudy, P.E. (1981). Structure, biosynthesis, and biodegradation of cutin and suberin. Annu. Rev. Plant Physiol. 32, 539-567.

Kolattukudy, P.E. (1984). Cutinases from fungi and pollen. In Lipases, B. Borgström and H. Brockman, eds (Amsterdam, The Netherlands: Elsevier), pp. 471-504.

Kolattukudy, P.E. (1985). Enzymatic penetration of the plant cuticle by fungal pathogens. Annu. Rev. Phytopathol. 23, 223-250.

Kolattukudy, P.E. (1996). Biosynthetic pathways of cutin and waxes, and their sensitivity to environmental stresses. In Plant Cuticles: An Integrated Functional Approach, G. Kerstiens, ed (Oxford, UK: BIOS Scientific Publishers), pp. 83-108.

Kolattukudy, P.E., Rogers, L.M., Li, D., Hwang, C.-S., and Flaishman, M.A. (1995). Surface signaling in pathogenesis. Proc. Natl. Acad. Sci. USA 92, 4080-4087.

Koncz, C., and Schell, J. (1986). The promoter of $T_{L}$-DNA gene 5 controls the tissue-specific expression of chimaeric genes carried by a novel type of Agrobacterium binary vector. Mol. Gen. Genet. 204, 383-396.

Koornneef, M., Hanhart, C.J ., and Thiel, F. (1989). A genetic and phenotypic description of eceriferum (cer) mutants in Arabidopsis thaliana. J . Hered. 80, 118-122.

Lemieux, B. (1996). Molecular genetics of epicuticular wax biosynthesis. Trends Plant Sci. 1, 312-318.

Lolle, S.J ., and Cheung, A.Y. (1993). Promiscuous germination and growth of wild-type pollen from Arabidopsis and related species on the shoot of the Arabidopsis mutant, fiddlehead. Dev. Biol. 155, 250-258.

Lolle, S.J ., and Pruitt, R.E. (1999). Epidermal cell interactions: Case for local talk. Trends Plant Sci. 4, 14-20.

Lolle, S.J ., Cheung, A.Y., and Sussex, I.M. (1992). Fiddlehead: An Arabidopsis mutant constitutively expressing an organ fusion program that involves interactions between epidermal cells. Dev. Biol. 152, 383-392.

Lolle, S.J., Berlyn, G.P., Engstrom, E.M., Krolikowski, K.A., Reiter, W.D., and Pruitt, R.E. (1997). Developmental regulation of cell interactions in the Arabidopsis fiddlehead1 mutant: A role for the epidermal cell wall and cuticle. Dev. Biol. 189, 311-321.

Lolle, S.J., Hsu, W., and Pruitt, R.E. (1998). Genetic analysis of organ fusion in Arabiopsis thaliana. Genetics 149, 607-619.

Maiti, I.B., Kolattukudy, P.E., and Shaykh, M. (1979). Purification and characterization of a novel cutinase from Nasturtium (Tropaeolum majus) pollen. Arch. Biochem. Biophys. 196, 412-423.

McNevin, J .-P., Woodward, W., Hannoufa, A., Feldmann, K.A., and Lemieux, B. (1993). Isolation and characterization of eceriferum (cer) mutants induced by T-DNA insertions in Arabidopsis thaliana. Genome 36, 610-618.

Mett, V.L., Lochhead, L.P., and Reynolds, P.H.S. (1993). Coppercontrollable gene expression system for whole plants. Proc. Natl. Acad. Sci. USA 90, 4567-4571.

Namai, T., Kato, T., Yamaguchi, Y., and Hirukawa, T. (1993). Antirice blast activity and resistance induction of C-18 oxygenated fatty acids. Biosci. Biotechnol. Biochem. 57, 611-613. 
Preuss, D., Lemieux, B., Yen, G., and Davis, R.W. (1993). A conditional sterile mutation eliminates surface components from Arabidopsis pollen and disrupts cell signalling during fertilization. Genes Dev. 7, 974-985.

Pruitt, R.E., Vielle-Calzada, J.-P., Ploense, S.E., Grossniklaus, U., and Lolle, S.J . (2000). FIDDLEHEAD, a gene required to suppress epidermal cell interactions in Arabidopsis, encodes a putative lipid biosynthetic enzyme. Proc. Natl. Acad. Sci. USA 97, 1311-1316.

Quadrano, R.S., and Shaw, S.L. (1997). Role of the cell wall in the determination of cell polarity and the plane of division in Fucus embryos. Trends Plant Sci. 2, 15-21.

Reynhard, E.C., and Riederer, M. (1991). Structures and molecular dynamics of the cuticular wax from leaves of Citrus auranticum $L$. J. Phys. D Appl. Phys. 24, 478-486.

Reynhard, E.C., and Riederer, M. (1994). Structures and molecular dynamics of the plant waxes. II. Cuticular waxes from leaves of Fagus sylvatica L. and Hordeum vulgare L. Eur. Biophys. J. 23, 59-70.

Reynolds, E.S. (1963). The use of lead citrate at high pH as an electron opaque stain in electron microscopy. J . Cell Biol. 17, 208-213.

Rhee, S.Y., and Somerville, C.R. (1998). Tetrad pollen formation in quartet mutants of Arabidopsis thaliana is associated with persistence of pectic polysaccharides of the pollen mother cell wall. Plant J . 15, 79-88.

Riederer, M., and Schreiber, L. (1995). Waxes: The transport barriers of plant cuticles. In Waxes: Chemistry, Molecular Biology, and Functions, R.J . Hamilton, ed (Dundee, Scotland: Oily Press), pp. 131-156.

Schreiber, L., Kirsch, T., and Riederer, M. (1996). Diffusion through cuticles: Principles and models. In Plant Cuticles: An Integrated Functional Approach, G. Kerstiens, ed (Oxford, UK: BIOS Scientific Publishers), pp. 109-120.

Schweizer, P., J eanguénat, A., Mösinger, E., and Métraux, J .-P. (1994). Plant protection by free cutin monomers in two cereal pathosystems. In Advances in Molecular Genetics of PlantMicrobe Interactions, M.J. Daniels, J.A. Downie, and A.E. Osbourn, eds (Dordrecht, The Netherlands: Kluwer Academic Publishers), pp. 371-374.

Schweizer, P., Felix, G., Buchala, A., Müller, C., and Métraux, J .-P. (1996a). Perception of cutin monomers by plant cells. Plant J. 10, 331-341.
Schweizer, P., J eanguénat, A., Whitacre, D., Métraux, J .-P., and Mösinger, E. (1996b). Induction of resistance in barley against Erysiphe graminis f. sp. hordei by free cutin monomers. Physiol. Mol. Plant Pathol. 49, 103-120.

Shinshi, H., Neuhaus, J .-M., Ryals, J., and Meins, F., J r. (1990). Structure of a tobacco endochitinase gene: Evidence that different chitinase genes can arise by transposition of sequences encoding a cysteine-rich domain. Plant Mol. Biol. 14, 357-368.

Sinha, N., and Lynch, M. (1998). Fused organs in the adherent1 mutant in maize show altered epidermal wall with no perturbations in tissue identities. Planta 206, 184-195.

Soliday, C.L., Flurkey, W.H., Okita, T.W., and Kolattukudy, P.E. (1984). Cloning and structure determination of a CDNA for cutinase, an enzyme involved in fungal penetration of plants. Proc. Natl. Acad. Sci. USA 81, 3939-3943.

Stephenson, M.B., and Hawes, M.C. (1994). Correlation of pectin methylesterase activity in root caps with root border cell separation. Plant Physiol. 106, 739-745.

Szymkowiak, E.A., and Sussex, I.M. (1996). What chimeras can tell us about plant development. Annu. Rev. Plant Physiol. Plant Mol. Biol. 47, 351-376.

Verbeke, J.A. (1992). Fusion events during floral morphogenesis. Annu. Rev. Plant Physiol. Plant Mol. Biol. 43, 583-598.

Walker, D.B., and Bruck, D.K. (1985). Incompetence of stem epidermal cells to dedifferentiate and graft. Can. J. Bot. 63, 21292132.

Warmke, H.E., and Lee, S.J . (1976). Improved staining procedures for semithin epoxy sections of plant tissues. Stain Technol. 51, 179-185.

Wolters-Arts, M., Lush, W.M., and Mariani, C. (1998). Lipids are required for directional pollen-tube growth. Nature 392, 818-821.

Yao, C., and Köller, W. (1995). Diversity of cutinases from plant pathogenic fungi: Different cutinases are expressed during saprophytic and pathogenic stages of Alternaria brassicicola. Mol. Plant-Microbe Interact. 8, 122-130.

Yephremov, A., Wisman, E., Huijser, P., Huijser, C., Wellesen, K., and Saedler, H. (1999). Characterization of the FIDDLEHEAD gene of Arabidopsis reveals a link between adhesion response and cell differentiation in the epidermis. Plant Cell 11, 2187-2201. 